\title{
The application of forest sustainable management framework and community participation adjacent to Doi Laung wildlife sanctuary, Thailand
}

\author{
Piyapit Khonkaen*1,2, Jie-Dar Cheng ${ }^{1}$ \\ ${ }^{1}$ National Chung-Hsing University, Taiwan \\ Department of Soil and Water Conservation \\ ${ }^{2}$ Maejo University Phrae Campus, Thailand \\ *Corresponding author's e-mail: piyapit@gmail.com
}

Keywords: conservation activities, forest health, group interview, species diversity, planning management.

\begin{abstract}
This paper present the data for monitoring forest conditions and forest resource management by a local community adjacent to the Doi Laung Wildlife Sanctuary, Huaimai Sub-district, Song District, Phrae Province, Thailand. This study uses quantitative forest surveys, interviews, discussions, and descriptions of the historical context of public participation in forest management including a detailed assessment of field conditions. The findings of a forest resources inventory show that (1) from the three sampled areas, Doi Laung Wildlife Sanctuary has highest richness, followed by village \#16 and \#14, and (2) Huaikhon \#16 implied the process of framework to maintain a healthy condition and response to community needs with collective management. The conceptual model assessment that links key group indicators and drivers is presented based on previously developed assessment models. The framework focuses on the best way to provide forest management, forest fire prevention, and firefighting as well as monitoring of Check-dam construction and other activities that support the recovery of the forest community. This paper demonstrates the general of an environmental assessment framework to applying organize environmental information to facilitate policy decision making for the sustainable development.
\end{abstract}

\section{Introduction}

People generally agree that sustainable forest management should be environmentally responsible, socially beneficial and economically viable to meet the needs of present and future generations. However, it is not always clear what this means in terms of forest management in the field (Hares 2009). An appropriate environmental assessment tool is a key step in assessment of human driven environmental problems related to spatial and social determinants by social movements for promoting sustainable development (Turner and Oakes 1989). An integrated framework has set of concepts and tools to perform assessments to understand the reasoning of the assessments focused on making decisions to resolve issues (Agyemang et al. 2007, Cormier and Suter II 2008, Daily et al. 2009). Community forests can be a significant component of conservation strategies focused on how land managers can target conservation investments based on the biological benefits of the plans (Margules and Pressey 2000, Naidoo et al. 2006, Lyman et al., 2011); these studies provided illustrative information for forest management developing the strategies to promote sustainable management of natural resources.

The forest policy in Thailand has been characterized by abrupt and sweeping changes in 1989 and the subsequent emergence of community forestry in the 1990s (Pye 2005). Government policies protect and conserve natural resources with the backing of NGOs. In the past, Huaimai (sub-district) was rich in resources even after the contract logging operations were completed and the nearby communities were allowed to cut the remaining trees resulting in the clearcutting of the forest, a long drought, and flooding. Doi Laung Wildlife Sanctuary was established on October 1, 1984 by the Royal Forest Department (RFD). The government and local communities hoped to conserve the forest and protect the sanctuary area for wildlife. This paper discusses how local communities participate and cooperate with government approaches to planning and management in nearby community forests that support sustainable social, cultural, economic, and ecological practices. The goals include framework guidelines designed to promote multiple policies and activities management. The framework had been developed for an integrated environmental assessment with a methodological included community with participation. Additionally, the problems and potential solutions related to forest management may have implications for other areas with similar socioeconomic conditions and similar needs for natural resource conservation that are based on sound scientific principles.

\section{Materials and Methods}

\section{Study area}

The study area is located at Huaimai (sub-district), Song District, Phrae, in northern Thailand (Fig. 1). The selected area of study 
represents existing phenomena of a forest community based on historical and current local community forest activities. First, Doi Laung Wildlife Sanctuary forest is characterized by bureau activities based on legislation. Second, Huaikhon \#14 village represent non-forest conservation activities. Third, Huaikhon \#16 village has forest conservation activities with most local communities managing the forest preservation system. We have assumed that Doi Laung Wildlife Sanctuary forest is the control measured over this study. Three plots comprised of mixed deciduous forest at the same altitude and were of similar tree community composition. The investigation was conducted from June-August 2007.

\section{Data collection and analysis}

The study sites were selected for the application of the framework and methods of community forest management. The process is one of learning among people and ecology to identify and discuss in terms related to community perception and the maintenance of natural assets. Figure 2 provides a flowchart outlining this research project. Five steps were followed to achieve the research goals.

Step 1. Identification: The first phase requires an exploration of a sustainable ecosystem management solution that addresses the actual ground situation while maintaining ecological integrity and sustainability of such services (Lü et al. 2011). This phase was also used to review and determine the magnitude of potential availability of the spatial and social determinants. Evaluation provides a means for a completed project, program, or policy including its design, implementation, and results (Kusek and Rist 2004). First, the three forests were selected: the Doi Laung Wildlife Sanctuary forest and the community forests of villages \#14 and \#16, as described earlier in this study. Twenty participants were selected and represented all major stakeholder groups to survey a wide variety of viewpoints as follows: elected local officials; officials of local, regional, and national government agencies; and local citizens. Last, the material was organized and grouped by information related to the various survey data. Further research is needed to quantify the capacity of various land-cover types to support various land use types and associated management techniques (De Groot et al. 2010).

Step 2. Quantification: a quantifiable measure was created and related to the actual forest condition capacity and processes derived from the interviews and monitoring data collected. This study explores the forest conditions and composition using a quadrate method. In each area of the sampling site (DoiLaung Wildlife Sanctuary, villages \#14, \#16); we set a plot of $40 \times 40 \mathrm{~m}$ (Fig. 1). Forest conditions were compared as follows: (1) height-class distribution of trees and sapling; (2) dbh-class distribution of trees and sapling; (3) density of trees; (4) basal area; and (5) the diversity index as suggested by Ludwig and Reynolds (1988) and Kent and Coker (1992).

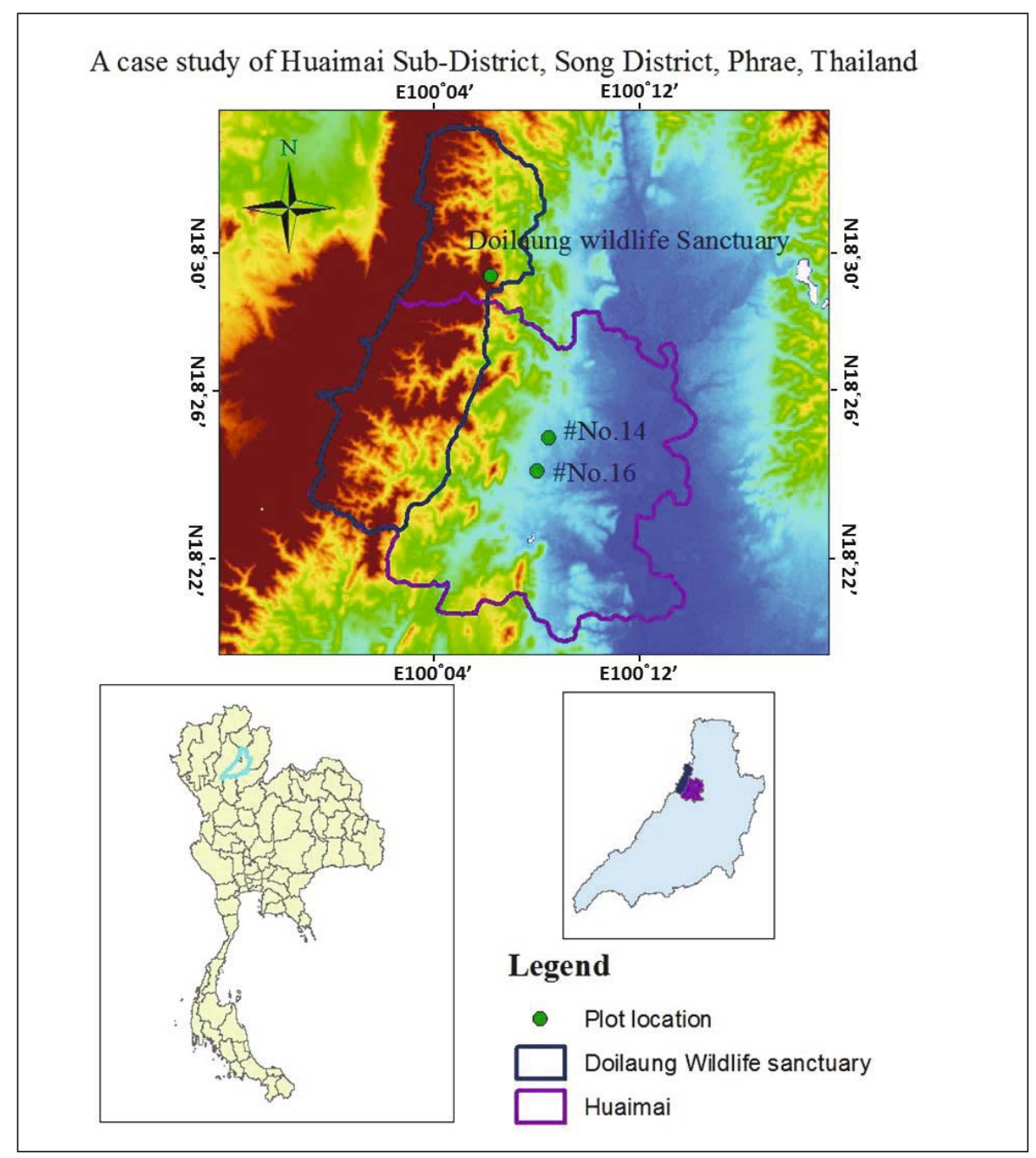

Fig. 1. The location map of the Doi Laung Sanctuary and Huaimai, Phrae Province, Thailand 
In-depth interviews, group discussions, and participant observations were used to collect information related to forest management practices by the communities, such as forest uses, rules, and institutions governing the use of the forests, silvicultural treatments and monitoring, and forest protection methods. There were 5-10 participants in each group whose comprised the focus group. The discussions were conducted with at least two contacts from each group. The interviews included village chairpersons, members of the village committees, and individuals who have in-depth understanding of history of forest management in their respective villages were selected. The open-ended questions were used to elicit information from the participants with traditional elders and members of village committees.

Step 3. Assessment: The performance assessments have been evaluated and resulted changes in forest conditions that were grouped by capacity under alternative action exposures and changes in effects of management activities. These data were used as case studies for an ongoing understanding and assessment of the actual implementation with community-based forest management of skills, knowledge, and assets. The assessment also focused on the impact on the forests and community-based forest activities and guidelines as well as an appropriate collection of information to be used during decision-making and provided for at local and regional scales (De Groot et al. 2010).

Step 4. Planning/Management: The analysis focused on identifying the collection, processing, and exploitation planning management. Resource managers need to manage information and knowledge resources effectively such as creating, sharing, and leveraging knowledge among communities, resource managers, and policy makers to be considered descriptive or analytical in planning and management. Information management is more concerned with establishing processes and systems to gather, organize, summarize, and package information that can be delivered to the decision makers. The risks involved in taking alternative actions as well as the social and economic advantages and disadvantages of management goals need to be evaluated.

Step 5. Suggestion: In light of the improvements in all processes, a need exists and is related to reviewing and improving forestry policies, strategies, and action plans with the participation of local organizations, governmental units, and other stakeholders. The appropriateness of the system used to improve and manage the forest conditions was assessed based on the capacity of individuals, groups, and organizations to create suggestions. This approach seeks to encourage desirable resource management outcomes to shift points of view to better align with new information and shared learning.

\section{Results and Discussions}

\section{Forest health and diversity of three forest areas}

$\mathrm{DBH}$ class distribution is a good indicator of the maturity and successional stage of forest units. Figure 3 illustrates the DBH-class distribution for the three forest plots studied. Trees with DBH class distribution over $30 \mathrm{~cm}$ are evenly distributed in the forests of both Doi Laung Wildlife Sanctuary and Huaikhon \#16. Forests in Huaikhon \#16 have had a longer time to establish community forests and therefore have a greater number of trees in all DBH size-classes in the 15-30 cm range than those in \#14. There is a slight difference in the DBH distribution of sampling trees within the two villages. Forests in Huaikhon \#14 have a greater number of trees at each DBH-class than those in Huaikhon \#16. The forest in Huaikhon $\# 14$ has the smallest number of trees with DBH from $15-30 \mathrm{~cm}$. However, the relationship between DBH-class distribution and height-class distribution differed for different three forest areas (Figs. 3 and 4).

A greater number of individuals are found in Huaikhon \#14 and \#16 when compared with the number of individuals found in the Doi Laung Wildlife Sanctuary with the highest number

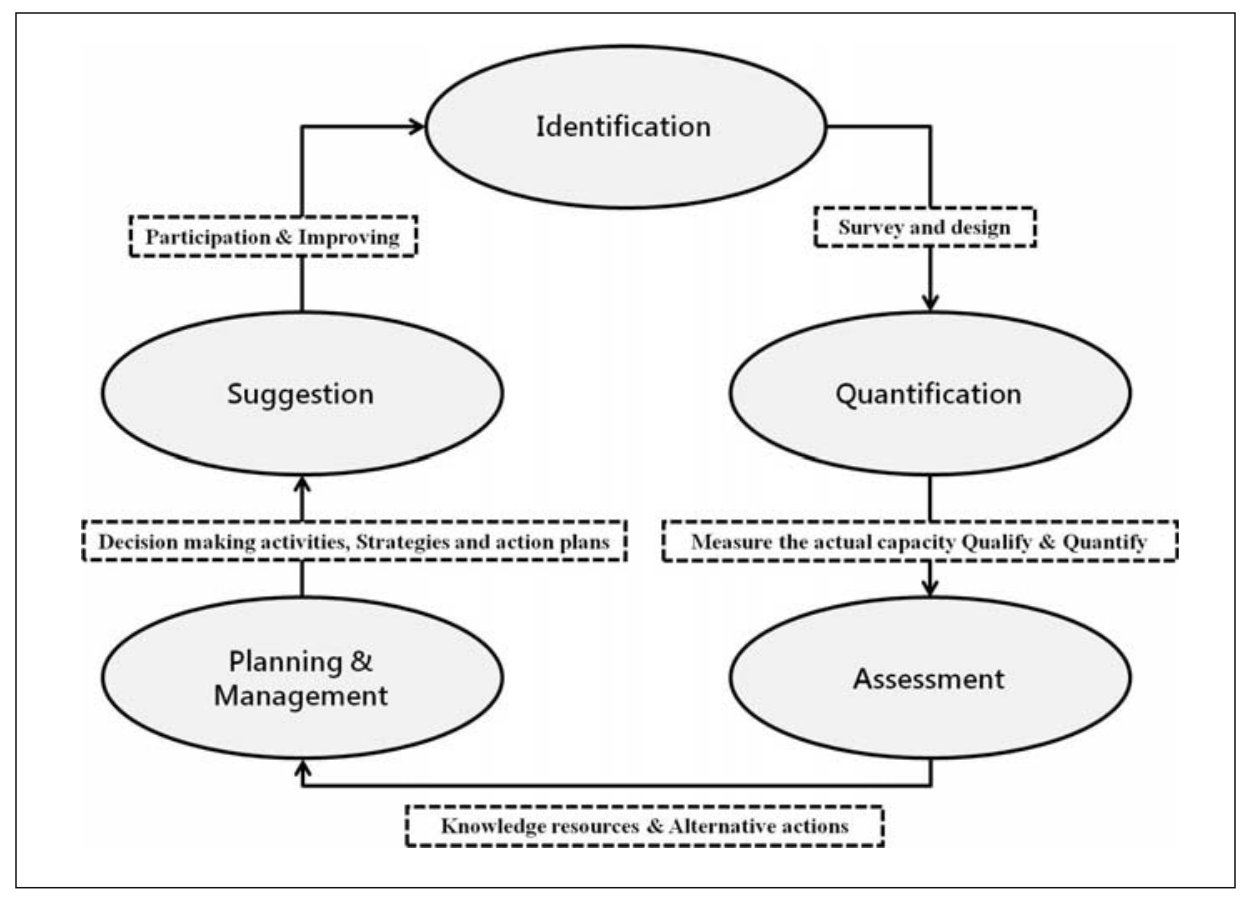

Fig. 2. The practical framework identifies and discusses the environmental assessment that addresses detection and solves an environmental problem 
of saplings in the Huaikhon \#14 forest. The successional stage of a forest also can be determined by comparing the average height of trees of a forest among the three plots. Figure 4 shows the height-class distribution of trees and samplings at the three sites. More than $50 \%$ of trees and saplings at all three sites were 5-10 $\mathrm{m}$ tall, which indicates a height distribution similar under different management practices. In this case, few differences exist in forest health between the forest areas of Huaikhon \#14 and \#16 when considering only height-class distribution.

Table 1 shows the number of tree species in each of the three plots as well as total tree density, total basal area, and species diversity. The basal areas of Huaikhon \#14 and \#16 community forests were similar, although the basal area of Doi Laung forest was much larger (Table 1). Table 1 show that DBH-class distribution and density of tree species (including trees, saplings, and seedling) was higher in \#14 forest than in \#16 forest, while the Doi Laung forest had the highest density. The \#14 forest had a higher tree density than \#16, while the highest tree density was found in the Doi Laung forest. Tree densities differed significantly between the Doi Laung forest and the other two forests with significantly lower densities of large trees in the \#14 and \#16 forests and a significantly lower density of small trees in the Doi Laung forest. Table 1 provides the species diversity indices of the three forest areas studied here with the Doi Laung forest having the highest and the Huaikhon \#14 forest having the lowest species diversity index, which was close to that of a natural forest. Forest regeneration considers sapling and seedling density as mentioned above (Table 1). Huaikhon \#14 and \#16 had the highest percentages of sapling and seedling species when compared to the total number of species within a particular forest unit implying that both these forest had good regeneration for many species. The condition of these community forests has improved over time as evidenced in the presence of many new young trees, grassy areas, and a robust amount of regeneration in the form of new seedlings.

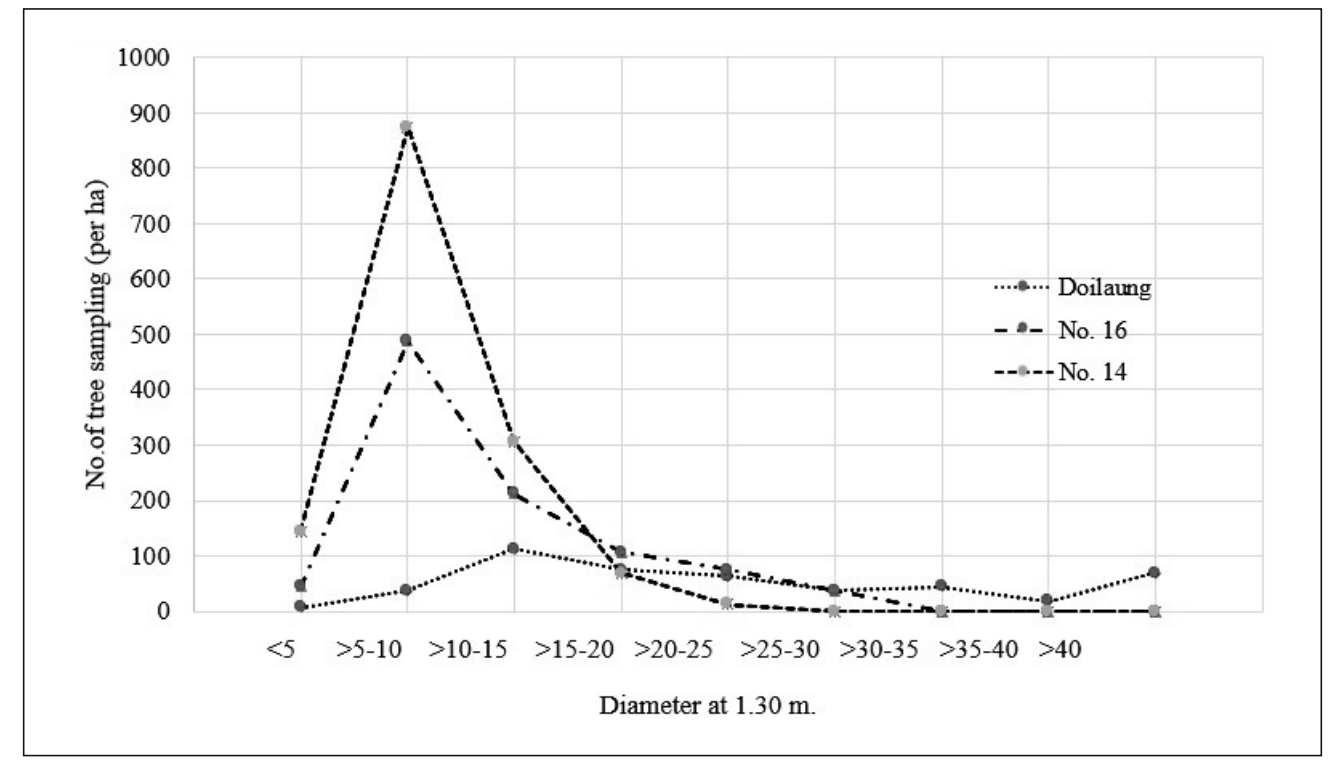

Fig. 3. DBH class distribution of trees and samplings in three forest plot

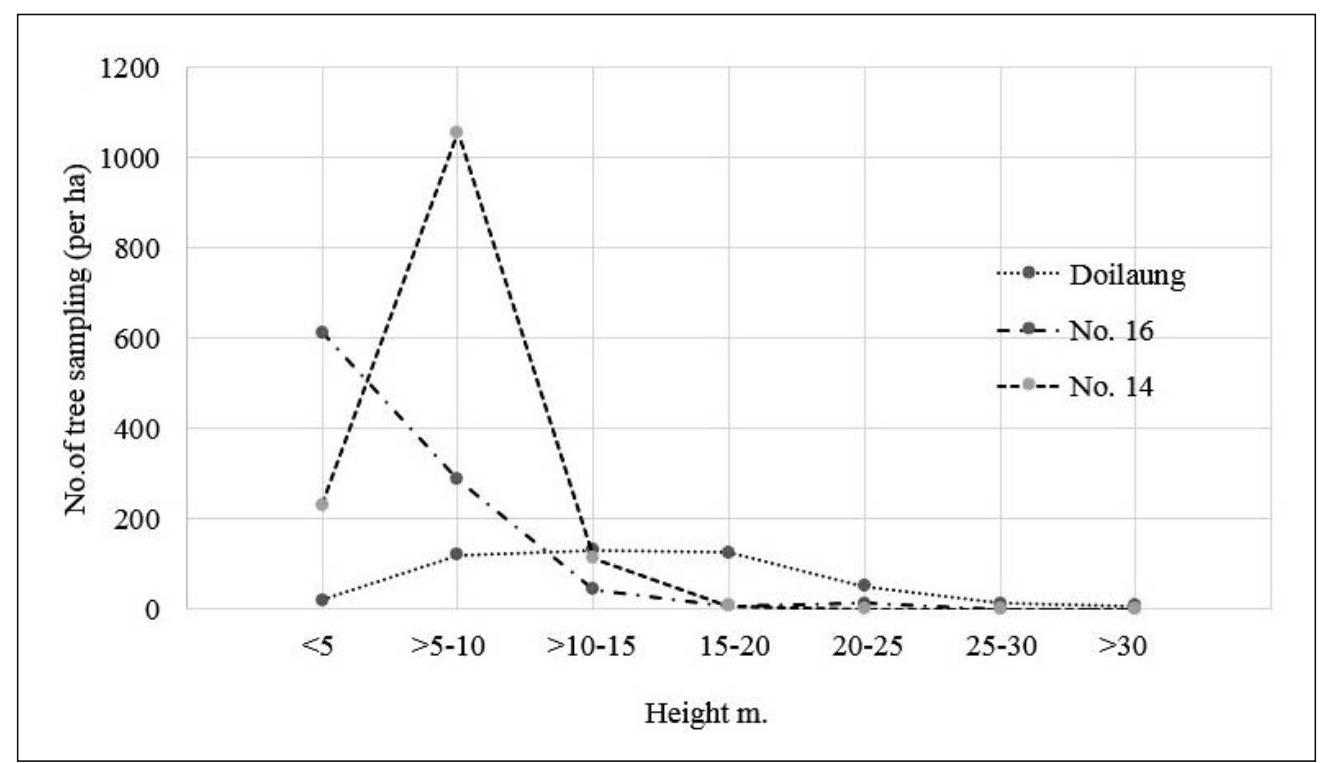

Fig. 4. Height-class distribution of trees and samplings of the three forest plots 


\section{Planning and Management}

Forest management was conducted by the community with cooperation and integration between the villagers to manage forest functions and activities within the forest sustainably. Based on the findings here, community members have an opportunity to provide input for the development of an adaptive management strategy and forest management plan. Detailed operational plans were used to manage the complex and changing environment. Group membership is an important component of social identity (Turner and Oakes 1989). Local people are thought to create subcultures based on their shared forest experiences, which leads to group-specific preferences related to forest management (Berninger et al. 2009). Table 2 outlines the process that prompted community forest development in forests surrounding the villages. The villagers participated in supervising the management of the community forest.

Community organization and the network of villages: Representatives of the Doi Laung Wildlife Sanctuary and members of the community forest committee held regular meetings and worked together. They used regulations to manage the conservation and use of resources. Additionally, the community had meetings to designate members of the community forest board who drafted rules and guidelines with the goal of conserving forest resources and that established penalties for anyone who violated the rules.
Conservation activities: The lives and livelihood of Huaikhon \#16 community depend on forests and the natural resources of the forests to provide them with food, shelter, medicine, and spirituality. Therefore, community members use these resources and have a great sense of caring about their sustainable use with the following timetable of activities (Table 3) throughout a year. Their methods of managing resources have been learned and accumulated over long periods and these communities have unique knowledge of forest resources. Members of community forest boards also develop conservation activities.

Forest fire prevention and the construction of fire lines during the dry season: The heads of villages and the villagers of Huaikhon \#16 continue to have the responsibility of providing fire protection for these forested areas. Villagers, students, youth groups, and the heads of villages cooperate to provide forest fire prevention and control in the summer for the community forest and they work together to conserve the forest by fragmenting the area with firebreaks from February-May every year.

Reforestation and survey: Huaikhon \#16 coordinate with the Doi Laung Wildlife Sanctuary, local administrative organizations, Phrae Province administrative organizations, and various private organizations to plan and carry out tree planting, forest management and extension, and establish tree planting programs every year especially on the Queen's birthday (12 August) and the King's birthday (5 December).

Table 1. General characteristics of the trees in Doi Laung Wildlife Sanctuary forest and in the community forests of Huaikhon \#14 and \#16

\begin{tabular}{|l|c|c|c|c|}
\hline \multicolumn{1}{|c|}{ Forest types } & No. of tree species & $\begin{array}{c}\text { Total basal area } \\
(\mathrm{m} 2 / \mathrm{ha})\end{array}$ & $\begin{array}{c}\text { Total density of all } \\
\text { tree species }(/ \mathrm{ha})\end{array}$ & $\begin{array}{c}\text { Species diversity } \\
\text { index }\left(\mathrm{H}^{\prime}\right)\end{array}$ \\
\hline Doi Laung Wildlife Sanctuary & 31 & 4.13 & 462.5 & 3.19 \\
\hline Huaikhon \#14 & 37 & 1.61 & $1,181.25$ & 2.50 \\
\hline Huaikhon \#16 & 29 & 2.05 & 962.5 & 2.64 \\
\hline
\end{tabular}

Table 2. Management status of Huaikhon \#16 village community forests

\begin{tabular}{|l|l|}
\hline \multicolumn{1}{|c|}{ Management component } & \multicolumn{1}{c|}{ Status } \\
\hline $\begin{array}{l}\text { Date the community began organizing their forest management } \\
\text { efforts }\end{array}$ & In the middle of the 2005 \\
\hline Reason for the initiation of community forest management & $\begin{array}{l}\text { A village leader organized the local people to support local } \\
\text { forest protection }\end{array}$ \\
\hline Reasons for management & $\begin{array}{l}\text { Rapid deforestation, forest fires, a need to protect forest } \\
\text { ecology }\end{array}$ \\
\hline Legal status & $\begin{array}{l}\text { No legal rights but encouraged the local community to protect } \\
\text { local forest ecosystems }\end{array}$ \\
\hline Type of community organization & Informal village community \\
\hline Protection system & Voluntary protection \\
\hline Interests of villagers for community forests & High \\
\hline
\end{tabular}

Table 3. Conservation network expansion and interaction of Huaikhon \#16 with other villages

\begin{tabular}{|l|l|}
\hline \multicolumn{1}{|c|}{ Activities } & \multicolumn{1}{c|}{ Objective } \\
\hline Conservation Extension & Providing an example of resource conservation to other villages. \\
\hline Training for other villages & Train volunteers to protect forests and wildlife. \\
\hline Persuasiveness & Convince other villages to participate in conservation activities. \\
\hline Public relations & $\begin{array}{l}\text { The members of a community forest management board assisting in the presentation } \\
\text { of conservation demonstration projects. }\end{array}$ \\
\hline
\end{tabular}


Monitoring Check-dam construction: Huaikhon \#14 and \#16 have joined to manage water resources by forming a "Dam Group". The headman, vice-headman, and representatives of the villagers have begun to consider monitoring dams to preserve water resources for irrigation with guidelines developed by the Dam Group organization. Currently, they are working to increase the network used to monitor Check-dam construction along the main river (the Huaikhon River) in this area in coordination with Huaikhon villages \#14, \#11, \#10, and \#3 as this river provides most of the water for these villages. These activities have promoted the cooperative management of water resources and community participation.

\section{Monitoring and Evaluation of the Benefits}

All of the interested parties have reached an agreement to coordinate the management of these forests collectively. Together, they have established forest resource management guidelines for tree planting, the prevention of forest fires, construction of firebreaks, resource surveys during the dry season and the monitoring of Check-dam construction and reforestation during the rainy season. The expectations of village leaders have helped achieve desirable outcomes that contribute to the communities reaching their developmental goals.

Coordination Guidelines: The local communities seek to protect the threatened forests and resources by linking conservation and local livelihood objectives (Agrawal and Gibson 1999, Li 2002). The heads of Huaikhon $\# 16$ have coordinated with villagers, collaborated with other villages, and encouraged conservation through coordination with non-governmental and government organizations such as the Doi Laung Wildlife Sanctuary, local administrative organizations, Phrae administrative organizations, and other private organizations to conserve resources and discuss conservation activities. This was especially emphasized at Huaikhon \#16 where cooperation within and among these villages seems to work well. Table 4 shows how conservation network has expanded from village \# 16 to other villages.

Monthly monitoring activities: The head of Huaikhon \#16 has coordinated with the heads of other villages, villagers, Doi Laung Wildlife Sanctuary, the local administrative organizations, Phrae province administration, and other private organizations to establish a yearly operational plan. Villages \#16 have held many activities related to conservation and the prevention of forest fires. In particular, by building and maintaining firebreaks as well as participating in firefighting activities have required collaboration with those villages. Table 4 shows the annual forest-related activities at Huaikhon \#16.

\section{Analysis of practical framework assessment}

The practical framework stands for identification, quantification, assessment, planning management, and suggestion. Figure 5 illustrates the application of the conceptual framework to summarize the results of the analysis of the environmental conditions and conservation activities in the studied areas. The resulting capacity framework is organized on existing concepts of community and collaborative capacity across a variety of public management and community development. The strength of the framework is that it simply shows the connections among people and the environment. This paper focuses on three areas of concern as well as their use as a reporting framework and an analytical tool.

The first phase, problem identification of Huaikhon \#14 and \#16 can be categorized into natural resources, economics, and management. After a review and a determination were made, the three plots were mixed deciduous forest at the same altitude and with similar tree community compositions. Table 5 provides a summary of biophysical conditions and a history of land and forests in the three areas. Upon further review and determination, Huaikhon \#14 has indicated decreasing forest area and less participation with forest management. On the other hand, Huaikhon \#16 has indicated a process with community forest management and increasing forest area. The research design as well as the identification approach to the practical framework within community forest management.

Doi Laung Wildlife Sanctuary forest is mature and a large basal area made up of large, mature trees even though plant density is low. This forest had the highest species diversity index of the three study areas and the Huaikhon \#16 community forest was in much better condition than Huaikhon \#14 in terms of basal area and species diversity indices. In comparison, \#16 and Doi Laung forests had similar diversity indices that indicate that the management of the community forest was successful in preserving plant diversity and the growth of large trees. The data collected from the focus groups illustrated improvements in forest management as experienced at Huaikhon \#14 and \#16. The use and conservation of the community forest areas was regulated primarily by the rules established by the village and their forest management committees. The villagers themselves delineated the locations of protected forests and no trees were allowed to be cut in protected areas, but villagers were usually able to gather non-timber forest products in most areas, although even this was forbidden in some areas.

The results show that Doi Laung Wildlife Sanctuary forest was more diverse than Huaikhon \#14 and \#16 community forests and Huaikhon \#16 was more diverse than Huaikhon \#14. Huaikhon \#16 community forests were managed by community regulations. These regulations provided guidelines and activities for forest protection, cooperation with government officers, the construction of firebreaks, and Check-dam construction, which were all designed to protect and conserve the forest community. The guidelines involving

Table 4. Yearly forest management activities at Huaikhon \#16

\begin{tabular}{|l|l|l|}
\hline \multicolumn{1}{|c|}{ Activities } & \multicolumn{1}{c|}{ Month } & \multicolumn{1}{c|}{ Time } \\
\hline Planting & June-September & One day every two months \\
\hline Prevention of forest fires & March-May & One day per month \\
\hline Check dam construction & March-August & One day every two months \\
\hline Forest surveys & Every 3 months & One day every three months \\
\hline Fire fighting & Mostly March-May & As needed \\
\hline Meetings & January-December & One day every two months \\
\hline
\end{tabular}


the state and the local communities were outlined in a formal agreement. This agreement is designed to coordinate forest maintenance activities and related forest resource management. The activities included tree planting and constructing fire lines during the dry season and fighting wildfires, monitoring the condition of check dams, and conducting forest surveys.

The main aim in collecting and analyzing this information is to provide a better understanding of management plans and techniques as well as to improve planning related to the use of land, water, and other resources of natural forests. The new forest management programs initiated in Huaikhon \#16 strongly focus on the development of forested areas in a way that sustains the local community. The use of forests to support these local communities is another factor that helps ensure the participation of the local people in the protection and management of forest resources. Therefore, recognizing the traditional participatory approaches and the local institutions in Huaikhon \#16 based on sustainable livelihood principles holds promise for sustainable forest management. Finally, the framework developed from this study provides useful information to everyone involved to help communities design appropriate guidelines for making environmental management decision.

The forest management guidelines were influenced by local group leaders and local people with decisions that had been made independently. This shows that these forests are being sustainably managed by local forest user groups. Based on this case study, we propose the following suggestions:

1. The Thai government should support and promote the activities of local communities and indigenous peoples in continued area management and maintenance including the establishment of community conservation areas allowing the members of local communities to manage natural resources themselves in an appropriate and sustainable manner.

2. The management concepts for forest areas outlined should be promoted and integrated into government policies and plans. These guidelines should be widely implemented, particularly in protected areas or parks where forest-dependent communities thrive. A model such as the one presented here will help clearly define land boundaries, which can prevent further encroachment on natural forests while at the same time help to secure the livelihoods of local communities. Government agencies and land managers should consider the development of impact and effectiveness assessment approaches to policies, plans, and forest restoration projects.

3. Local organizations, particularly sub-district administration organizations, should be involved, and provide support for these activities, including providing financial assistance and the positive outcomes that result from community forest management.

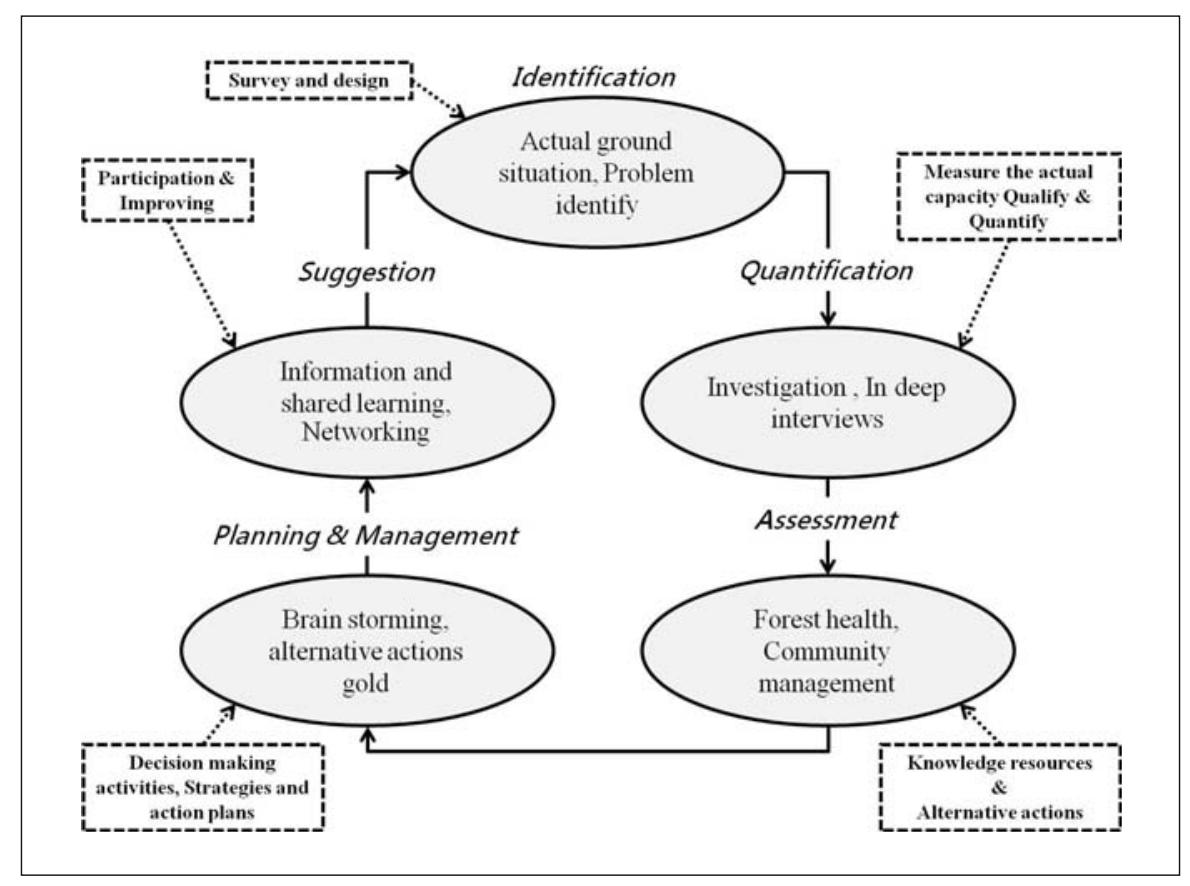

Fig. 5. Application of a practical framework is an indicated linkage of components related to the assessment and management framework process

Table 5. Summary of biophysical conditions with land-use history in Huaikhon \#14 and \#16

\begin{tabular}{|l|l|l|l|}
\hline Characteristics & Doi Laung Wildlife Sanctuary & Huaikhon village \#14 & Huaikhon village \#16 \\
\hline \multirow{2}{*}{ Biophysical conditions } & Elevation: $300-1,200 \mathrm{~m} \mathrm{msl}$ & Elevation: 200-520 m msl & Elevation: 210-550 m msl \\
\cline { 2 - 4 } & Crown cover: 40-95\% & Crown cover: $30-80 \%$ & Crown cover: 30-80\% \\
\hline Forest ecosystem type & Moist deciduous forest & Deciduous forest & Deciduous forest \\
\hline History of land use & $\begin{array}{l}\text { Under shifting by Huaikhon } \\
\text { watershed }\end{array}$ & $\begin{array}{l}\text { Under shifting cultivation then } \\
\text { lay in fallow for 5-15 years }\end{array}$ & $\begin{array}{l}\text { Under shifting cultivation then } \\
\text { lay in fallow for 5-15 years }\end{array}$ \\
\hline
\end{tabular}




\section{Conclusions}

As a result of these findings, the framework of environmental assessment provides based on sound principles with other input for scientifically informed dimensional decision-making. Therefore, a fully integrated framework will provide a clearer path for community participation and sustainable development that motivates a cooperative integration of framework designed to guide the management of forest resources. Although this framework is common and simplistic, it captures the multiple relationships that exist within a forest management framework and suggests as both a reporting and analytical framework. While we may focus on the relationships between human and natural environment, it is clear that practical framework made them to be based on wider social and ecological processes.

\section{Acknowledgments}

We thank the community participants in Huaimai for their involvement and willingness to provide information used in this research and the authorities at Doi Laung Wildlife Sanctuary, the local government of Huaimai, and the Protected Area Regional Office 13 Phrae Branch for granting access to GIS and forest management data.

\section{References}

Agrawal, A. \& Gibson, C.C. (1999). Enchantment and disenchantment: the role of community in natural resource conservation, World Development, 27, pp. 629-649. doi:10.1016/S0305750X(98)00161-2

Daily, C.G., Polasky, S., Goldstein, J., Kareiva M.P., Mooney, A.H., Pejchar, L., Ricketts, H.T., Salzman, J. \& Shallenberger, R. (2009). Ecosystem services in decision making: time to deliver, Frontiers in Ecology and the Environment, 7, 21-28. http://dx.doi. org/10.1890/080025.

Agyemang, I., McDonald, A. \& Carver, S. (2007). Application of the DPSIR framework to environmental degradation assessment in northern Ghana, Natural Resources Forum, 31, 212-225. doi: 10.1111/j.1477-8947.2007.00152.x.

Ludwig, A.J. \& Reynolds, J.F. (1988). Statistical ecology: A primer on methods and computing, in: Ecology Statistical Method, John Wiley \& Sons, Inc, New York, pp. 1-44.

Turner J.C. \& Oakes, P.J. (1989). Self-categorization theory and social influence. 2nd edition In: The Psychology of group influence. Erlbaum, Hillsdale. pp. 233-275.
Berninger, K., Kneeshaw, D. \& Messier, C. (2009). The role of cultural models in local perceptions of SFM-differences and similarities of interest groups from three boreal regions, Journal of Environmental Management, 90, pp. 740-751. doi:10.1016/j. jenvman.2008.01.004

Kent, M. \& Coker, P. (1992). Vegetation description and analysis: A practical approach, 2nd edition, in: Chapter 1 The nature of quantitative plant ecology and vegetation science, John Wiley \& Sons, New York, pp. 1-22.

Kusek, J.Z. \& Rist, R.C. (2004). A handbook for development practitioners: ten Steps to a Results-Based Monitoring and Evaluation System: a hand- book for development practitioners, in: Step 5: Planning for Improvement-Selecting Results Targets. Washington, DC: The World Bank, pp. 90-95.

Li, M.T. (2002). Engaging simplifications: community-based resource management, market processes and state agendas in Upland Southeast Asia, World Development, 30, 265-283, doi:10.1016/ S0305-750X(01)00103-6.

Lyman, M.W., Evans, J.R. \& Mytar, M. (2011). Community forests: needs and resources for creating and managing community forests, in: Complete Finding, New England: Community Forest Collaborative, The Trust for Public Land (TPL). pp. 15-24.

Margules, C.R. \& Pressey, R.L. (2000). Systematic conservation planning, Nature, pp. 405, 243-253. doi:10.1038/35012251.

Hares, M. (2009). Forest conflict in Thailand: Northern minorities in focus, Environmental Management, 43, pp. 381-395. doi:10.1007/s00267-008-9239-7.

Pye, O. (2005). Strategic groups and counter-strategic formation in Thai Forestry. Bonn, Germany: Department of Southeast Asian Studies Bonn University, Southeast Asian Studies Working Paper No. 22.

Naidoo, R., Balmford, A., Ferraro J.P., Polasky, S., Ricketts, H.T. \& Rouget, M. (2006). Integrating economic costs into conservation planning, Trends in Ecology \& Evolution, 21, pp. 681-687. doi:10.1016/j.tree.2006.10.003.

De Groot, R.S., Alkemadeb, R., Braatc, L., Heina, L. \& Willemen, L.. (2010). Challenges in integrating the concept of ecosystem services and values in landscape planning, management and decision making, Ecological Complexity, 7, pp. 260-272. doi:10.1016/j.ecocom.2009.10.006.

Cormier, M.S. \& Suter II, W.G. (2008). A framework for fully integrating environmental assessment, Environmental Management, 42, pp. 543-556. doi: 10.1007/s00267-008-9138-y.

Lü, Y., Fu, B., Wei, W., Yu, X. \& Sun, R. (2011). Major ecosystems in China: dynamics and challenges for sustainable management, Environmental Management, 48, pp. 13-27. doi:10.1007/ s00267-011-9684-6. 